\title{
Visible Study of Mercuric Ion in Brassica Juncea Living Cells and Plants Using a Fluorescent Dye
}

\author{
Pin-san XU $\mathrm{XU}^{1,2}$, Zheng-yao ZHANG ${ }^{1}$, Ling-yao $\mathrm{LI}^{2}$ and Yu-bo LIU ${ }^{1, a,{ }^{*}}$ \\ ${ }^{1}$ School of Life Science and Medicine, Dalian University of Technology, Panjin 122406, \\ People's Republic of China \\ ${ }^{2}$ School of Life Science and Technology, Dalian University of Technology, Dalian \\ 116024, People's Republic of China \\ aliuyubo@dlut.edu.cn \\ ${ }^{*}$ Corresponding author
}

Keywords: Brassica juncea, Mercuric ion, Fluorescent dye.

\begin{abstract}
Concern over mercury cytotoxicity inside live specimens has encouraged the development of efficient methods for the in vivo detection of this heavy metal. In this study, by using the previous developed fluorescence dye EPNP (2,6-bis-(4'-peperazino-N'-butyl-1',8'-naphthalimide) dimethylpyridine) as a highly selective and sensitive probe for mercuric ions $\left(\mathrm{Hg}^{2+}\right)$, the images of $\mathrm{Hg}^{2+}$ distribution and transportation in the living cells and plants of Brassica juncea were obtained. After $10,50,100 \mu \mathrm{M} \mathrm{Hg}^{2+}$ exposure, gradually increased fluorescence was detected in B. juncea living cells loaded with EPNP dye. Intracellular $\mathrm{Hg}^{2+}$ time-dependent fluorescence enhancement of EPNP was also observed in B. juncea cells. Furthermore, images of confocal microscope shown that $\mathrm{Hg}^{2+}$ was found to mostly accumulate in lytic vacuole but not in the nucleus or mitochondria. In addition, a concentration-dependent rise of fluorescence was observed when the EPNP interacted with an increasing concentration of $\mathrm{Hg}^{2+}$ in the plants of $\mathrm{B}$. juncea. These results provided direct experimental evidences for the distribution, translocation and transportation of $\mathrm{Hg}^{2+}$ in B. juncea. EPNP would be used as a chemical tool for the study of phytoremediation related researches.
\end{abstract}

\section{Introduction}

Mercury, a dangerous and widespread global pollutant, has been increasingly released to the environment by anthropogenic activities. The global contamination by mercury has caused public anxiety [1]. Mercuric ions $\left(\mathrm{Hg}^{2+}\right)$ are the most stable form of inorganic mercury, and can be accumulated by plants, animals, and finally human beings [2]. However, comparing with methylmercury, the toxicity of $\mathrm{Hg}^{2+}$ has not been well investigated. As a strong phytotoxic, $\mathrm{Hg}^{2+}$ tends to form covalent bonds with DNA, and induces oxidative stress in several plants . It was also reported that $\mathrm{Hg}^{2+}$ could bind to water channel proteins, induce stomata to close and disrupt water flow in vascular tissues [3]. Moreover, plants exposure to $\mathrm{Hg}^{2+}$ led to modification of organelles and other physiological processes [4]. $\mathrm{Hg}^{2+}$ and $\mathrm{Hg}^{2+}$ conjugate might enter the food chain through human or animal uptake. Therefore, plants pose health risks if they accumulated and transported $\mathrm{Hg}^{2+}$. Based on these potential risks, the explorations aimed at developing selective and efficient methods to monitor $\mathrm{Hg}^{2+}$ translocation, transportation and distribution in higher plants have been the topic of various studies[5].

Fluorescence imaging is currently the most powerful technique available for this application. Highly selective and sensitive fluorescent dyes have been extensively 
investigated for continuous observation of intracellular processes in living cells [6]. In previous studies, a molecular fluorescence dye, EPNP (2,6-bis-(4'-peperazino-N'-butyl-1',8'-naphthalimide)dimethylpyridine) was applied to the cultured cells. The membrane permeability, low toxicity, slow bleaching/fading, and high sensitivity to nanomolar concentrations $\mathrm{Hg} 2+$ of this fluorescence dye were confirmed in both mammalian cells and plant cells [7]. At the same cell density, fluorescence of EPNP inside live cells in the presence of $\mathrm{Hg}^{2+}$ were much higher than those of $\mathrm{Ca}^{2+}, \mathrm{Mg} 2+, \mathrm{Zn}^{2+}, \mathrm{Cu}^{2+}, \mathrm{Mn}^{2+}$, and $\mathrm{Ni}^{2+}$, indicating the selectivity of this probe [8].

Since Brassica juncea (B. juncea) plants have higher biomass and faster growth rates compared to other hyperaccumulator plants for heavy metals like mercury, B. juncea has been extensively used for studies on accumulation and phytoremediation of $\mathrm{Hg}$ enriched soils [9]. As B. juncea is a high-level $\mathrm{Hg}$ accumulating plant (accumulates up to 2570 and $27,900 \mathrm{mg} \mathrm{kg}-1$ in shoots and roots) [10], is fast growing, and produces high biomass [11], in the present study this species is, therefore, a good candidate for investigation of the physiology and toxicity of $\mathrm{Hg}^{2+}$ and $\mathrm{Hg}^{2+}$ conjugate following plant exposure. To investigate $\mathrm{Hg}^{2+}$ in B. juncea at the cellular and tissular levels, EPNP was used to develop a visual technique for real time and online analysis. Our results provided direct evidence for the localization of $\mathrm{Hg}^{2+}$ in the lysosomes of $\mathrm{B}$. juncea suspension cells. Furthermore, the distribution, translocation and transportation of $\mathrm{Hg}^{2+}$ in living plant was visible.

\section{Material and methods}

\section{Chemicals and plant material}

B. juncea seeds were obtained from Institute of Geochemistry Chinese Academy of Science (Guiyang, China). EPNP was synthetized as follows: 4-Piperazino-N-butyl-1,8-naphthalimide (149 mg, $0.44 \mathrm{mmol}$ ) was dissolved in acetonitrile (30 mL), and then, 2,6-dichlorometh- ylpyridine $(35.2 \mathrm{mg}, 0.20 \mathrm{mmol})$ was added; after the mixture was stirred and refluxed for $10 \mathrm{~h}$ under a nitrogen atmosphere, the mixture was cooled to room temperature to afford a yellow solid after filtration, which was purified by silica gel column chromatography using chloroform/methanol (5:1, v/v) as the eluent to afford EPNP [8]. Nuclei probe (DAPI, 4', 6-diamidino-2-phenylindole) [12], mitochondrial probe (Mito-Tracker), lysosomal probe (Lyso-Tracker) were purchased from Beyotime Biotechnology Inc. (Nanjing, China).

\section{Cell Suspension Cultures}

After seeds germination, petiole and leaf segments of $B$. juncea were considered as explants for callus development. Callus growth was monitored by measuring dry weight of the developed callus. Suspension cultures were initiated by inoculation of one gram of callus into a $125 \mathrm{ml}$ Erlenmeyer flask containing $25 \mathrm{ml}$ of liquid Murashige-Skoog (MS) medium. The liquid medium was filtered, and separated cells were used for further experiments.

\section{Visualization of Mercury in B. Juncea Suspension Cells}

Cells of $B$. juncea were treated with $10 \mu \mathrm{M}$ EPNP for $30 \mathrm{~min}$ and then washed twice with phosphate buffer solution (PBS). Fresh MS medium was added with 0, 10, 50, 100 $\mu \mathrm{M} \mathrm{HgCl}_{2}$. After $0,0.5,1$, or $3 \mathrm{~h}$ of exposure, cells were washed several times with phosphate buffer saline (PBS) until neutral conditions ( $\mathrm{pH}$ is about 7.0) were approached. $\mathrm{Hg}^{2+}$ was visualized in cells using the fluorescence dye EPNP according to 
a previous publication . Briefly, the cultured cells were incubated in the presence of 10 $\mu \mathrm{M}$ EPNP for $30 \mathrm{~min}$, washed three times with PBS and observed using a Nikon TE2000 inverted fluorescence microscope (Nikon, Japan) fitted with a wide-band cube U-MWU filter. All these dyeing experiments were performed independently for three times.

\section{In Vivo Fluorescence Imaging of Mercury}

The plants of $\mathrm{B}$. juncea were grown on solid MS medium containing $0,10,50,100 \mu \mathrm{M}$ $\mathrm{HgCl}_{2}$ for different time $(0.5-3 \mathrm{~h})$. The roots of the plants were then washed with PBS for 3 times. Kodak Carestream Molecular Imaging System (Carestream Health, Inc., USA) was used to observe the translocation, transportation, and distribution of $\mathrm{Hg}^{2+}$ in vivo. Three independent experiments were performed.

\section{Results}

\section{Concentration- and Time-dependent $\mathrm{Hg}^{2+}$ Distribution in Live Cells of $\mathrm{B}$. juncea.}

The distribution of $\mathrm{Hg}^{2+}$ in $\mathrm{B}$. juncea suspension cells at various dosages and series of exposure times was shown in Fig. 1 and Fig. 2, respectively. No obvious fluorescence was detected in living cells without $\mathrm{Hg}^{2+}$ exposure. Green fluorescence was initially observed in B. juncea cells which treated with $10 \mu \mathrm{M} \mathrm{HgCl}_{2}$ for 30 min (Fig. 1B). At higher concentrations or longer treatments of $\mathrm{HgCl}_{2}$, the fluorescence intensity was obviously increased. Fig. 2D showed the fluorescence image at $3 \mathrm{~h}$ after $10 \mu \mathrm{M} \mathrm{HgCl}_{2}$ treatment.
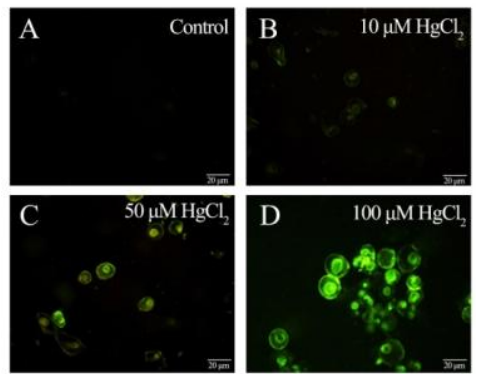

Fig. 1. Concentration-dependent fluorescence microphotographs of $\mathrm{HgCl}_{2}$ uptake by Brassica juncea living cells. Images were taken by an inverted fluorescence microscope. (A) Amplificatory image of control cells which was cultured without $\mathrm{HgCl}_{2}$. (B-D) Cells were cultured in with $10 \mu \mathrm{M} \mathrm{EPNP}$. After $30 \mathrm{~min}$ of incubation, cells were washed, and then, indicated doses of $\mathrm{HgCl}_{2}$ was added, respectively. Images were taken 30 min after $\mathrm{HgCl}_{2}$ treatment.
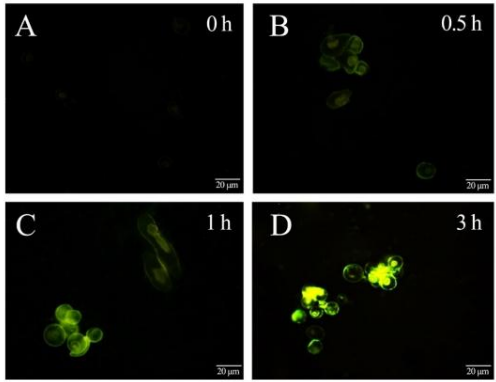

Fig. 2. Time-dependent fluorescence microphotographs of $\mathrm{HgCl}_{2}$ uptake by Brassica juncea living cells. Images were taken by an inverted fluorescence microscope. Cells were cultured in with $10 \mu \mathrm{M}$ EPNP. After 30 min of incubation, cells were washed, and then, $10 \mu \mathrm{M} \mathrm{HgCl}_{2}$ was added. Scanning was taken continuously, (A) before $\mathrm{HgCl}_{2}$ was added; (B) $0.5 \mathrm{~h}$ after exposure to $10 \mu \mathrm{M} \mathrm{HgCl}_{2}$; (C) $1 \mathrm{~h}$ after exposure to $10 \mu \mathrm{M} \mathrm{HgCl}_{2}$; (D) $3 \mathrm{~h}$ after exposure to $10 \mu \mathrm{M} \mathrm{HgCl}_{2}$ 


\section{Subcellular localization of $\mathbf{H g}^{2+} \mathrm{B}$. juncea living cells.}

To determine the subcellular distribution of $\mathrm{Hg}^{2+}$ in $B$. juncea living cells, fluorescence imaging for $\mathrm{Hg}^{2+}$ was carried out in living cells using scanning confocal microscopy. According to the results in Fig. 1, concentration-dependent experiments showed that $100 \mu \mathrm{M} \mathrm{Hg}^{2+}$ was sufficient to load cells with stain. DAPI, Lyso-Tracker, Mito-Tracker were used for labeling nuclei, lysosome and mitochondria, respectively. The results were shown in Fig. 3. The overlay images showed significant colocalization of EPNP and Lyso-Tracker. Small extent of colocalization was found between EPNP and DAPI suggesting that $\mathrm{Hg}^{2+}$ mostly accumulated in lysosomes. This result indicated that lysosome played an important role in enriching $\mathrm{Hg}^{2+}$ in $B$. juncea cells.

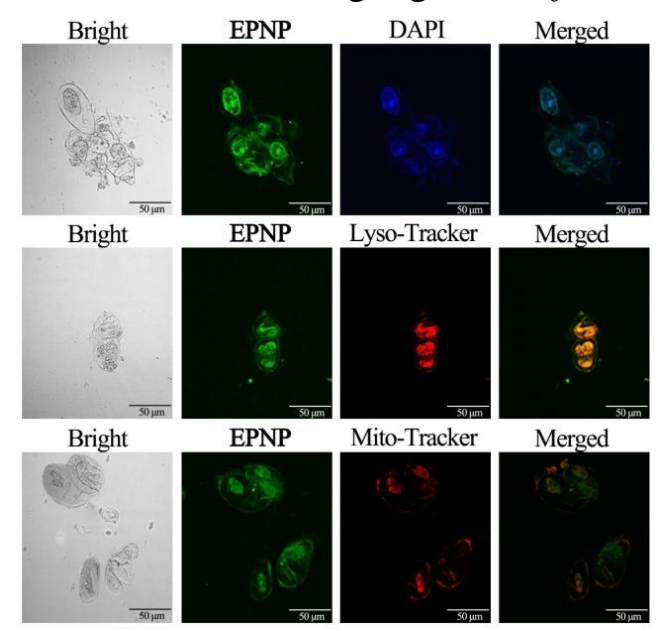

Fig. 3. Laser confocal fluorescence images for the sensors of $\mathrm{Hg}^{2+}$ in living Brassica juncea cells. Brassica juncea cells that were incubated with $10 \mu \mathrm{M}$ EPNP for 30 min and then incubated with $\mathrm{HgCl}_{2}$ $(10 \mu \mathrm{M})$ in MS medium for $30 \mathrm{~min}$. Nucleus (blue), lysosomes (red) or mitochondria (red) was labeled with indicated dyes for $30 \mathrm{~min}$ before fluorescence imaging. Confocal fluorescence images, bright-field transmission images and merging images were shown.

\section{Real-time in Vivo Monitoring of $\mathbf{H g}^{2+}$ Translocation and Transportation in the Plants of B. juncea.}

In order to investigate the translocation and transportation of $\mathrm{Hg}^{2+}$ in vivo, the plants of B. juncea were grown on MS medium containing a series concentration of $\mathrm{HgCl}_{2}$. Then the plants were loaded with $10 \mu \mathrm{M}$ EPNP dye for $30 \mathrm{~min}$. No obvious fluorescence was detected in control group which was not treated with $\mathrm{HgCl}_{2}$ (Fig. 4). Significant $\mathrm{Hg}^{2+}$-induced fluorescence was visible from hypocotyl to stem of the plants. Fluorescence intensity was higher in plants that were treated with 50 or $100 \mu \mathrm{M} \mathrm{Hg}^{2+}$ than those treated with $10 \mu \mathrm{M} \mathrm{Hg}^{2+}$.

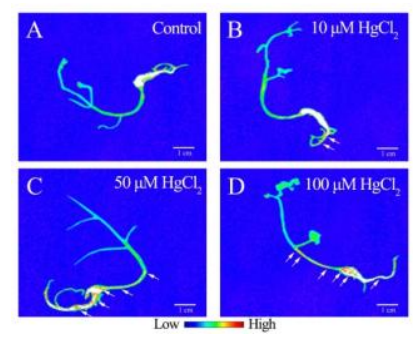

Fig. 4. In vivo imaging of $\mathrm{Hg}^{2+}$ in the plants of Brassica juncea. Plants treated with (A) $0 \mu \mathrm{M}$, (B) $10 \mu \mathrm{M}$, (C) $50 \mu \mathrm{M}$, (D) $100 \mu \mathrm{M}$ of $\mathrm{HgCl}_{2}$ for $30 \mathrm{~min} .10 \mu \mathrm{M}$ EPNP was added for dyeing. Then the roots of the plants were washed with PBS for 3 times. Kodak Molecular Imaging System was used for imaging. 


\section{Discussion}

The toxic exposure to mercury provide motivation to explore new methods for monitoring aqueous $\mathrm{Hg}^{2+}$ from biological and environmental samples [1]. Mercury uptake induced a significant phytotoxicity and reduced in both biomass and leaf relative water content in $\mathrm{B}$. juncea. Fluorescent sensors are emerging as key tools for the visualization of $\mathrm{Hg}^{2+}$ in live species. In the present study, we performed the real-time analysis of the distribution, translocation and transportation of $\mathrm{Hg}^{2+}$ in living cells and plants of B. juncea.

At 0.5 to $3 \mathrm{~h}$ after treatment with $10 \mu \mathrm{M} \mathrm{HgCl}_{2}, \mathrm{Hg}^{2+}$ was observed in living cells of B. juncea as an increase in fluorescence. Because of the low density of the cultured suspension cells, it was difficult to load these cells with stain. Time- and concentration-dependent experiments were carried out to conform the dyeing concentration and time of EPNP in the suspension cells of B. juncea. Our findings in Fig. 2 demonstrated the stability of EPNP was maintained within 0.5 to $3 \mathrm{~h}$. It means that the chromophore of this dye was not decomposed in the suspend cells of B. juncea, and made it possible to visualize the variation of $\mathrm{Hg}^{2+}$ in plant cell by using EPNP as a probe.

Notably, the fluorescence of EPNP concentrated in the middle of cell in Fig. 1 and 2. Nevertheless, due to the marginalization of organelles in mature plant cells we could not hastily conclude that $\mathrm{Hg}^{2+}$ was located in the nuclei of $\mathrm{B}$. juncea cell. To investigate the subcellular localization of $\mathrm{Hg}^{2+}$, the probes of different organelles were used. EPNP was mostly located at the lysosomes in $\mathrm{B}$. juncea living cells, demonstrating that $\mathrm{Hg}^{2+}$ was mostly transported into lysosomes. It meant that lysosome played an important role in enriching $\mathrm{Hg}^{2+}$ in $\mathrm{B}$. juncea cells. Lysosomes are components of the endocytic pathway responsible for storage and processing of digestive enzymes and for terminal degradation as well as absorption of exogenous and endogenous macromolecules. Probably because of the marvelous stability of lysosomal membrane, lysosomes can accommodate quantities of $\mathrm{Hg}^{2+}$ in $\mathrm{B}$. juncea cells. It also indicated that the stability of lysosomal membrane could be a sensitive stress index in biomonitoring heavy metal pollution.

In conclusion, the fluorescent dye EPNP facilitates the sensitive and easy detection of intracellular $\mathrm{Hg}^{2+}$ in B. juncea living cells and plants. Therefore, subsequent hyperaccumulator studies of $\mathrm{Hg}^{2+}$ could benefit from the use of this fluorescence technique. Because the toxicological and enriched effects of $\mathrm{Hg}^{2+}$ are remarkably similar across a range of plant species (i.e., Chrysopogon zizanioides, and Hydrilla verticillata), examining the distribution, translocation and transportation of $\mathrm{Hg}^{2+}$ in $\mathrm{B}$. juncea after mercury exposure will advance the current understanding of the mechanisms underlying $\mathrm{Hg}^{2+}$ toxicity and enrichment in plants.

\section{Acknowledgement}

The authors would like to gratefully acknowledge support from National Natural Science Foundation of China (21502015), and the Doctoral Scientific Research Foundation of Liaoning Province (201501169).

\section{References}

[1] Tchounwou, P.B., et al., Review: Environmental exposure to mercury and its toxicopathologic implications for public health. Environ. Toxicol. 18(2013) 149-175. 
[2] Mudgal, V., et al., Effect of toxic metals on human health. Open. Nutrac. J. 3 (2010) 94-99.

[3] Dave, N., et al., Regenerable DNA-functionalized hydrogels for ultrasensitive, instrument-free mercury (II) detection and removal in water. J. Am. Chem. Soc. 132(2010) 12668-12673.

[4] Meng, D.K., J. Chen, and Z.M. Yang, Enhancement of tolerance of Indian mustard (Brassica juncea) to mercury by carbon monoxide. J. Hazard. Mater. 186 (2011) 1823-1829.

[5] Liu, D., et al., Effects of $\mathrm{Mg}^{2+}, \mathrm{Co}^{2+}$, and $\mathrm{Hg}^{2+}$ on the nucleus and nucleolus in root tip cells of Allium cepa. B. Environ. Contam. Tox. 55 (1995) 779-787.

[6] Quang, D.T. and J.S. Kim, Fluoro-and chromogenic chemodosimeters for heavy metal ion detection in solution and biospecimens. Chem. Rev. 110 (2010) 6280-6301.

[7] Guo, X., X. Qian, and L. Jia, A highly selective and sensitive fluorescent chemosensor for $\mathrm{Hg} 2+$ in neutral buffer aqueous solution. J. Am. Chem. Soc. 126 (2004) 2272-2273.

[8] Zhang, Z., et al., Visible study of mercuric ion and its conjugate in living cells of mammals and plants. Chem. Res. Toxicol. 18 (2005) 1814-1820.

[9] Su, Y., et al., Phytoextraction and accumulation of mercury in three plant species: Indian mustard (Brassica juncea), beard grass (Polypogon monospeliensis), and Chinese brake fern (Pteris vittata). In. J. Phytorem. 10 (2008) 547-560.

[10] Shiyab, S., et al., Phytotoxicity of mercury in Indian mustard (Brassica juncea L.). Ecotox. Environ. Safe. 72 (2009) 619-625.

[11] Singh, S. and S. Sinha, Accumulation of metals and its effects in Brassica juncea (L.) Czern. (cv. Rohini) grown on various amendments of tannery waste. Ecotox. Environ. Safe. 6 2(2005) 118-127.

[12] James, T.W. and C. Jope, Visualization by fluorescence of chloroplast DNA in higher plants by means of the DNA-specific probe 4'6-diamidino-2-phenylindole. The J. Cell. Biol. 79 (1978) 623-630. 